\title{
Erratum to: Effects of horizontal console position on operator muscular stress during abdominal ultrasonic diagnosis
}

\author{
Hiroyuki Suzuki • Takayoshi Saito • \\ Yoshihiro Shimomura $\cdot$ Tetsuo Katsuura
}

Published online: 4 March 2014

(C) The Japan Society of Ultrasonics in Medicine 2014

\section{Erratum to: J Med Ultrasonics}

\section{DOI 10.1007/s10396-013-0502-z}

The original version of this article unfortunately contained errors.

In Fig. 4, "Trapezius" should be "Trapezius (upper)".

In the Discussion section, in the first paragraph, in the second sentence, the words "and rotation angles" should be deleted.
Also in the Discussion section, in the second paragraph, in the second sentence, "rearpositions" should be "rear positions".

In Figs. 7 and 8, "Left Trapezius" should be "Left upper trapezius", "left Flexor digitorum Superficialis" should be "Left erector spinae", and "Right Flexor digitorum Superficialis" should be "Right erector spinae".

The online version of the original article can be found under doi:10.1007/s10396-013-0502-z.

H. Suzuki $(\square) \cdot$ T. Saito

Design Section, Marketing Division, Business Strategy

Department, Hitachi Aloka Medical, Ltd., 6-22-1 Mure,

Mitaka-Shi, Tokyo 181-8622, Japan

e-mail: suzu1912@hitachi-aloka.co.jp

Y. Shimomura · T. Katsuura

Graduate School of Engineering, Chiba University, Chiba, Japan 